\title{
Waiting tolerance: Ramp delay vs. freeway congestion
}

\author{
David Levinson *, Kathleen Harder, John Bloomfield, Kathy Carlson
}

Department of Civil Engineering, University of Minnesota, 500 Pillsbury Drive SE, Minneapolis, MN 55455, USA

Received 19 January 2004; received in revised form 18 August 2005; accepted 19 August 2005

\begin{abstract}
Waiting at ramp meters and traveling on freeways were tested using a computer administered stated preference (CASP) survey and a virtual experience stated preference (VESP) method employing a driving simulator. The selections varied in the number of minutes waiting at a ramp meter with vehicle speed once on the freeway. The subjects ranked the selections in order of preference. The results were statistically analyzed using a binary logit model controlling for demographics, socioeconomic characteristics, daily travel time, and personality scores. The results by the CASP method displayed a preference for freeway congestion to ramp delay, but opposite results were obtained by the VESP method. A number of reasons are posited to explain the difference, but the results indicate that method of stated preference data collection can significantly affect conclusions drawn.
\end{abstract}

(C) 2005 Elsevier Ltd. All rights reserved.

Keywords: Ramp meters; Personality; Stated preference; Driving simulator; Travel time

\section{Introduction}

Waiting is a part of life; demands and desires cannot be satisfied instantaneously. One must wait at service counters, professional offices, and at traffic signals. Individuals accept many common types of waiting conditions; yet complain about waiting at ramp meters to enter a freeway. This paper examines whether specific socioeconomic, demographic, or personality traits affect preference for slow moving traffic conditions over waiting at a ramp meter and driving in faster freeway conditions. This research decomposes driver preferences for in-vehicle travel time, in particular comparing freeway free-flow traffic conditions, congested traffic conditions, and time spent waiting at ramp meters to enter the freeway.

Ramp meters are traffic signals placed at the entrance points to limited access roadways intended to control the entrance rate of vehicles in order to maintain free-flowing travel conditions on the main road. Meters prevent a large number of vehicles from simultaneously merging onto the thoroughfare; reducing the potential for rear-end collisions. First implemented in the 1960s in Chicago, Detroit, and Los Angeles, they have since been deployed in at least twenty metropolitan areas in the United States (Pearson, Black, \& Wanat, 2001). Efficient

\footnotetext{
* Corresponding author. Tel.: +1 6126256354.

E-mail address: levin031@umn.edu (D. Levinson).
} 
use of ramp metering can reduce total system travel time, accidents, fuel consumption and vehicular emissions (Chaudhary \& Messer, 2000). Many studies have determined that proper ramp metering results in a better overall traffic flow during periods of traffic congestion (Chen, Jia, \& Varaiya, 2001; Levinson \& Zhang, 2005; Wu, 2001). Ramp metering has its negative side. Ramp metering may cause some drivers to change their route to other arterials causing congestion or increase safety concerns on these routes. Metering has been shown to encourage fewer and longer trips since it tends to benefit through traffic over local traffic (Zhang \& Levinson, 2002). Queues spilling back from ramp meters may result in queues interfering with arterial or local streets performance. Inequity occurs in the system, since some drivers are required to wait. As a result, ramp metering is still not accepted by the driving public in many cities, as stated by Piotrowicz and Robinson (1995), "To the public, ramp meters are often seen as a constraint on a roadway normally associated with a high degree of freedom."

There are several rationales as to why people should favor metering. First, it may be individually rational in that for most drivers, metering is simply delayed gratification, a driver must wait now in order to benefit later (assuming everyone else waits as well). Second, there is an aspect of social dilemma: driver A waits $t$ seconds so that driver B saves $t+x$ seconds, and the collective delay is lower with, than without, metering. There is evidence that both of these are the case, though this study only tests the first rationale.

D'Arcier (2000) proposed three main factors responsible for variations in day-to-day preferences or decisions: socioeconomic conditions, such as educational level and income; demographics, such as age, sex, resident type and location; and psycho-sociological determinants, such as lifestyle, opinions, and aspirations. All three factors were analyzed in this study. As stated by Stern and Richardson (2002), "A better understanding of travel behavior will improve travel demand forecasting and the assessment of emerging transport policies ..."

This study asked drivers to rate and rank four choice conditions with varying ramp meter wait times. The first experiment set ramp wait times at 0,2, 4, and $6 \mathrm{~min}$, and freeway travel times at 20,15, 12, and $10 \mathrm{~min}$. A second experiment set ramp wait times at 0,2, 4, and $6 \mathrm{~min}$ and freeway travel times at 20, 18, 16, and $14 \mathrm{~min}$. A longer wait time at the ramp meters was associated with a faster freeway speed (less congestion) for drivers. The travel distance remained the same for all four conditions in both experiments at $16.2 \mathrm{~km}$ (10 miles), but the travel speed varied from 48 to $97 \mathrm{~km} / \mathrm{h}(30-60 \mathrm{mph})$. Most metering systems are dynamic, so the actual wait depends on traffic levels, though, 2, 4, or 6 min (and longer) were not uncommon in the Twin Cities case prior to the shutdown and study in 2000 . New metering algorithms in place since after the shutdown have capped ramp wait at 4 min.

Stated preference (SP) surveys entered travel behavior research in the 1970s and their use increased dramatically in the 1990s (Hensher \& Battelino, 1997; Polak \& Jones, 1997; Stopher \& Zmud, 2001). Stated preference refers to measuring intention if the options concern behavioral alternatives, and it refers to measuring attitudes if the options concern conditions. SP surveys ask individuals to rate or rank or otherwise report their preferences on a few select alternatives in a controlled environment. In contrast, revealed preference (RP) refers to reported or measured behavior in actual conditions, where researchers observe what the subject actually does, not what they say they would do. Louviere, Hensher, and Joffre (2000) explains the significance and validity of using stated preference surveys in comparison with revealed preference surveys: SP surveys are beneficial when new attributes or products are introduced into the marketplace and when revealed preference data is time consuming or expensive to collect. In this case both rationales justify use of stated preference, we cannot easily test alternative ramp meter timings on actual commutes, as these are centrally controlled, and the alternatives considered do not appear in actual conditions.

The two types of SP experiments used in this study consisted of a computer administered stated preference (CASP) questionnaire and the use of a driving simulator, called virtual experience stated preference (VESP). Subjects rated on a scale from 1 to 7 (best), their opinion of the four choice conditions and then ranked the four conditions in order of most preferred. To better understand what affects preferences, the subjects were also asked to complete a NEO Five-Factor Inventory personality test.

One of the key factors in travel behavior and preference that has not been sufficiently investigated is personality. Many psychologists summarize an individual's personality into five main traits. Moberg (1999) summarizes the history of the Five-Factor Model; personality traits have been classified as virtues that are formulated due to hereditary and environmental influences and are firmly established by the age of thirty. 
The NEO Five-Factor Inventory personality questionnaire (FFI), which consists of 60-questions (see Buchanan (2001) and Costa \& McCrae (1991) for details), presents a widely used overall assessment of the individual's personality with minimal completion and scoring time. Many researchers have verified this questionnaire or a variation of this questionnaire with other personality models and have found them to be comparable (Tokar, Fischer, Snell, \& Harik-Williams, 1999). The questions are based on a five point scale ranging from strongly disagree to strongly agree. Several studies have shown that driving behavior correlates with personality (Arthur \& Graziano, 1996; Cellar, Nelson, \& Yorke, 2000), however to the best of our knowledge, no research has yet correlated travel behavior or preference with this type of data. One can speculate on the personality differences that may cause some individuals to prefer waiting to driving in a complex environment (e.g. the sensation averse) and others to prefer driving in more congested conditions to waiting (e.g. sensation seekers), but this paper refrains from making specific hypotheses on this, rather it poses the question as an exploration.

Subjects for this study were commuters in the Minneapolis-St. Paul metropolitan area. Prior to Fall 2000, the Minneapolis-St. Paul metropolitan area ramp meters were programmed to allow the freeway to flow as freely as possible with delay being imposed on drivers waiting at the ramp meters. Driver's dislike of ramp meters was voiced so loudly in the metro area that in October and November, 2000, all the ramp meters were shut off for an eight-week study. The controversy around the ramp meters provided an opportunity to conduct this study, but may have affected perceptions of the metering system.

The methodology behind the study for the CASP and VESP surveys and the choice set conditions for the experiments are presented in the next section. The model, hypotheses, and the results from the statistical analysis are in subsequent sections. The implications of the results are discussed, and then the paper is summarized and some conclusions presented.

\section{Methodology}

Stated preference surveys in prior research have been presented in paper format, computer format, or by telephone contact. This research used a computer administered stated preference (CASP) method and a new method, which we call virtual experience stated preference (VESP) that has the subjects experience the conditions in a wrap-around driving simulator. Both methods were used to determine subjects' preferences for either waiting at a ramp meter for 0-6 min combined with driving on the freeway at speeds of $48 \mathrm{~km} / \mathrm{h}$ (30 mph) to $97 \mathrm{~km} / \mathrm{h}(60 \mathrm{mph})$ respectively. The ideal condition is no waiting at a ramp meter combined with traveling at free-flow speed on the freeway, which few if any drivers actually experience. The subjects had to decide their trade-off point between ramp wait times with freeway travel speed. This section presents the subject selection process and then the detailed methodology of the CASP and VESP experiments respectively.

\subsection{Subject selection process}

A set of 15,288 non-student, non-faculty names was obtained from the Office of Institutional Research and Reporting at the University of Minnesota-Twin Cities Campus. Table 1 displays the subject selection process

Table 1

Summary of CASP subject selection process

\begin{tabular}{lr}
\hline Total number of names available & 15,288 \\
\hline Eliminated subjects outside of metropolitan area & 5404 \\
Eliminated subjects in Civil Engineering Department & 19 \\
Eliminated subjects in pilot study & 100 \\
Remaining available subjects & 9765 \\
Subjects receiving emails & 1308 \\
Subjects expressing interest in study & 209 \\
Subjects selected for the study & 89 \\
Subjects participating in the study & 69 \\
Subjects completing all requested information & 44 \\
\hline
\end{tabular}


for the CASP experiment. Subjects were randomly selected and emailed regarding participation in the CASP survey. Participants were required to hold a valid driver's license and drive to work. A pilot study was done to check the computer program and time requirements for completion of all requested information. One hundred subjects were emailed requesting their participation in the pilot study. Sixteen subjects were scheduled for December 18-20, 2002. Three subjects did not show and one did not complete the personality questionnaire. Twelve subjects successfully completed all questionnaires and surveys. After successful operation of the CASP, another 1308 subjects were emailed. Eighty-nine subjects were scheduled for January 14-16, 2003. Fifteen from the selected group did not appear and it was revealed another 5 subjects did not commute by motor vehicle. The remaining 69 subjects participated in the CASP survey and were paid $\$ 10$ for their time of approximately 15-20 min for completing the questionnaires.

The VESP \#1 and \#2 subjects were randomly selected in the same procedure from the remaining 8457 names, plus phone interviews were conducted to screen out non-driver commuters and drivers with a possibility of suffering simulator motion sickness.

\subsection{Computer administered stated preference ( $C A S P$ )}

The computer administered stated preference method used computer presentation of questionnaires implemented into a Microsoft Access database at the University of Minnesota in Minneapolis. The first two screens were entry into the survey, followed by 12-questions pertaining to their attitude about their commute, traffic congestion, ramp meters, public transit, and waiting in lines. The fourth to seventh screens requested basic demographic information, such as sex, age, educational level, number of household members and vehicles, annual household income, and household vehicles. Next the survey presented 16 screens of various bar charts with the color blue representing highway travel time and the color red representing time waiting at ramp meters. The alternatives were arranged using Latin Squares design to avoid order effects. Selections were presented individually, and subjects were asked to rate on a scale from 1 to 7 (best) their opinion of: 0,2 , 4, or $6 \mathrm{~min}$ of ramp wait with increasing freeway travel speed: $48 \mathrm{~km} / \mathrm{h}(30 \mathrm{mph}), 64 \mathrm{~km} / \mathrm{h}(40 \mathrm{mph}), 80 \mathrm{~km} / \mathrm{h}$ $(50 \mathrm{mph})$, or $97 \mathrm{~km} / \mathrm{h}(60 \mathrm{mph})$, respectively. Total travel times were 20, 17, 16 and $16 \mathrm{~min}$, respectively. The total travel distance remained constant at $16.2 \mathrm{~km}$ (10 miles). Then the subjects were presented a screen with all four previous selections together and asked to rank the four selections in order of preference, with 1 being their most preferred, etc., as shown in Fig. 1. The ranking results from this set of selections are known as Experiment \#1.

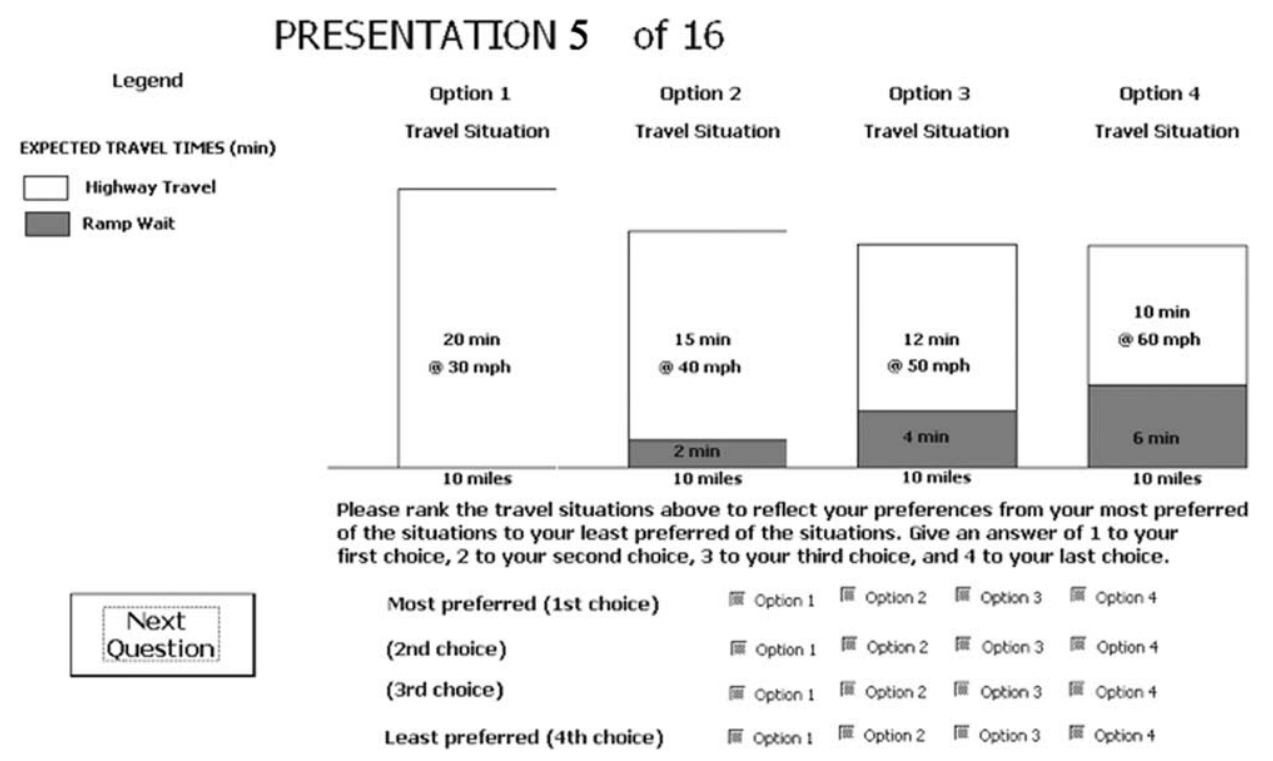

Fig. 1. Computer screen displaying selection choices for first condition set. 


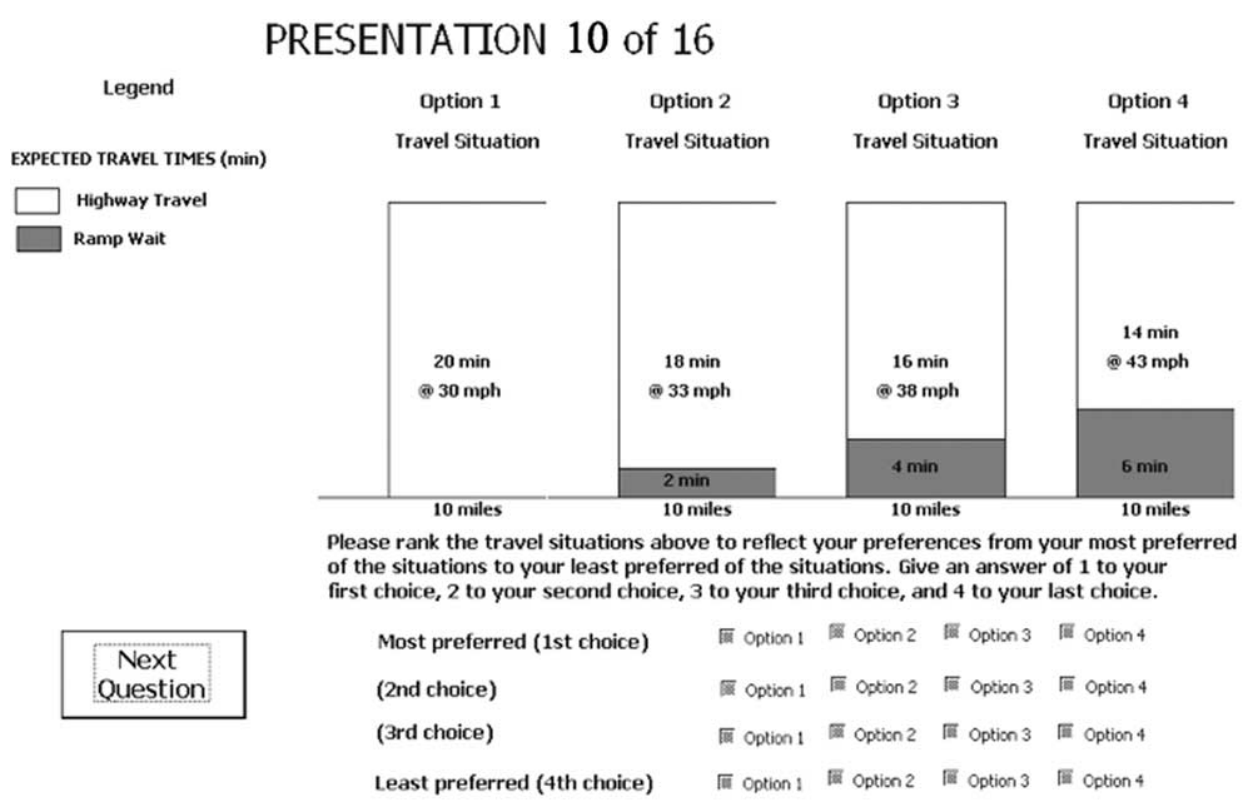

Fig. 2. Computer screen displaying selection choices for second condition set.

Next the subjects were presented four individual selections and asked to rate again ramp waits of $0,2,4$, and $6 \mathrm{~min}$, but this time the travel speeds were $48 \mathrm{~km} / \mathrm{h}(30 \mathrm{mph}), 53 \mathrm{~km} / \mathrm{h}(33 \mathrm{mph}), 61 \mathrm{~km} / \mathrm{h}(38 \mathrm{mph})$, and $69 \mathrm{~km} / \mathrm{h}(43 \mathrm{mph})$ respectively. This allowed the travel time to remain constant at $20 \mathrm{~min}$ and the travel distance to remain constant at $16.2 \mathrm{~km}$ (10 miles). The subjects were asked to rank the second set of four selections in order of their preference. The ranking results from this set of selections are known as Experiment \#2. Fig. 2 is the CASP presentation screen of the second experiment conditions.

Continuing on, the subjects were presented with four selections at the same time displaying ramp waits double the time of the first set of four selections $(0,4,8$, and $12 \mathrm{~min}$, respectively), with speeds and travel distance remaining the same and were asked to rank this set (Experiment 1b). Next subjects were presented with four selections displaying ramp wait time triple of the first set of four selections with speeds and travel distance remaining the same and were asked to rank this set (Experiment 1c). The next four screens presented four conditions with various combinations of ramp wait and varying highway speeds representative of light (97$120 \mathrm{~km} / \mathrm{h}$ or $60-75 \mathrm{mph}$ ), medium (64-97 km/h or 40-60 mph), and heavy (24-64 km/h or 15-40 mph) congestion levels (Experiments 3a-3d). The results of these studies are presented in Levinson, Harder, Bloomfield, and Winiarczyk (2005), and are not included here for reasons of space and clarity. The subjects were then asked to complete the 60-question NEO Five-Factor Inventory. The last screen thanked them for their participation.

This study will analyze the results from the ranking selections for the first and second set of selections, Experiments \#1 and \#2. Some subjects did not complete the surveys, travel diaries, personality test, or the profile questionnaire in their entirety, thus the final results display a smaller sample size of 44 individuals.

\subsection{Virtual experience stated preference (VESP)}

VESP \#1 had forty-two subjects appear for participation from March 10-14, 2003. The simulator software crashed on six subjects and four subjects experienced motion sickness, thus these participants were not included in the study, leaving 32 subjects to complete the experiment. The 32 subjects were asked to complete a one-day travel diary, the demographic and socioeconomic survey, the NEO Five-Factor Inventory, and the attitude questionnaire, either before or after their driving experience. Some subjects did not complete the surveys, travel diaries, personality test, and profile questionnaire in their entirety, thus the final results display a smaller sample size of 17 individuals. VESP \#2 had 21 subjects appear for participation from March 24-April 11, 2003 and 15 subjects from August 8-21, 2003. VESP \#2 had simulator software and motion sickness 
complications, as well. VESP \#2 had 8 of the 21 subjects and 9 of the 15 subjects complete the simulation experiment and all the requested information in its entirety for a total of 17 subjects. The VESP \#1 and \#2 subjects spent approximately $2 \mathrm{~h}$ at the research facility and received $\$ 50$ for their time.

The virtual driving simulation method consisted of a full-size 2002 Saturn SCI coupe, five flat-panel screens each $1.433 \mathrm{~m}$ (4.7-ft.) in height by $1.981 \mathrm{~m}$ (6.5-ft.) in width set $40.64 \mathrm{~cm}$ (16 in.) above ground level providing a 210-deg forward view, five projectors, two $12.70 \mathrm{~cm}$ (5-in.) LCD screens represented the vehicle's side view mirrors, and a $3.048 \mathrm{~m}(10-\mathrm{ft}$.) in height by $2.286 \mathrm{~m}(7.5-\mathrm{ft}$.) in width screen provided rear-view images which were seen in the vehicle's rear-view mirror. (AutoSim, 2002). The vehicle operated as it would in actual conditions with brakes, steering, acceleration, and a low-frequency vibration. Road, traffic, and engine sounds were emitted from four speakers. The clock and radio in the vehicle were not working, but the subjects were allowed to keep their watches. Fig. 3 is a photo of the virtual driving simulator.

The VESP subjects experienced "real-time" conditions. The four conditions were each presented randomly using Latin Squares. The ramp wait began the condition, followed by either stop-and-go or free flowing traffic appropriately, with any congestion occurring during the middle of the trip. The traffic speed was not constant throughout the driving experience for the VESP subjects. The subjects then rated each condition on a scale from 1 to 7 (best). After completion of the four conditions, the subjects ranked the conditions in order of their preference. The subjects in the VESP \#1 method experienced the first set of conditions that were presented to the CASP Experiment \#1 subjects. The VESP \#1 subjects experienced either: 0, 2, 4, or 6 min of ramp waits, followed by travel speeds of either: $48 \mathrm{~km} / \mathrm{h}(30 \mathrm{mph}), 64 \mathrm{~km} / \mathrm{h}(40 \mathrm{mph}), 80 \mathrm{~km} / \mathrm{h}(50 \mathrm{mph})$, and $97 \mathrm{~km} / \mathrm{h}$ $(60 \mathrm{mph})$ respectively. Total travel times were $20 \mathrm{~min}$ for $0 \mathrm{~min}$ of ramp wait, $17 \mathrm{~min}$ for $2 \mathrm{~min}$ of ramp wait, and decreased to $16 \mathrm{~min}$ for ramp waits of 4 and $6 \mathrm{~min}$. The total travel distance remained constant at $16.2 \mathrm{~km}$ (10 miles). The VESP \#2 subjects had the same procedure and requirements as the VESP \#1 subjects. The only difference was that the VESP \#2 subjects repeated the CASP Experiment \#2 choice set conditions. The choice set conditions consisted of equal total travel times of $20 \mathrm{~min}$ with ramp wait times of $0,2,4$, and 6 min and freeway travel times of 20,18, 16, and $14 \mathrm{~min}$, respectively. The travel distance remained constant at $16.2 \mathrm{~km}$ (10 miles) with travel speeds of $48 \mathrm{~km} / \mathrm{h}(30 \mathrm{mph}), 53 \mathrm{~km} / \mathrm{h}(33 \mathrm{mph}), 61 \mathrm{~km} / \mathrm{h}(38 \mathrm{mph})$, and $69 \mathrm{~km} / \mathrm{h}$ (43 $\mathrm{mph}$ ) respectively. In the VESP experiments, which involved a driving simulator and active driving on the part of the subject, the actual times might vary slightly due to the randomness within the simulator, as well as the driving strategy the subject pursues, though the use of other vehicles as a rolling roadblock kept the freeway times generally within a minute of designed total travel times in VESP \#1 and within $1.6 \mathrm{~min}$ of designed times in VESP \#2, as detailed in Levinson et al. (2005).

\section{Model}

The model for this study was:

$$
U=f(F, R, N, E, O, S, A, V, C, T)
$$

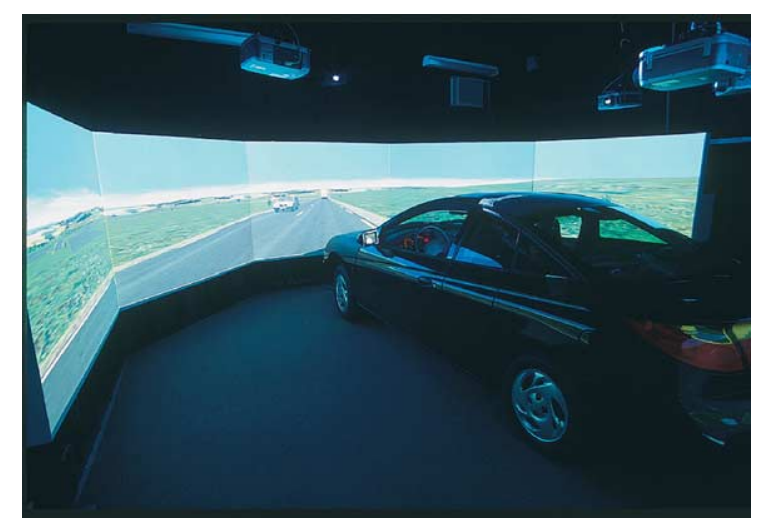

Fig. 3. Virtual driving simulator. Source: HumanFIRST Program, Available from www.humanfirst.umn.edu/Facilities/index.html. 
where:

$U \quad$ preference travel time utility

$F \quad$ freeway travel time (min)

$R \quad$ ramp wait time (min)

$N \quad$ personality Neuroticism score

$E \quad$ personality Extraversion score

$O$ personality Openness score

$S \quad$ subject's $\operatorname{Sex}(1=$ male, $0=$ female $)$

$A \quad$ subject's Age (years)

$V \quad$ average age of all household Vehicles in service (years)

$C$ one-way Commute time, home to work ( $\mathrm{min})$

$T \quad$ total daily travel time (min)

It is assumed that people optimize utility, but that utility varies for different individuals.

The results from the CASP and VESP surveys for the ranking of the four choice conditions as shown in Figs. 1 and 2 and in Tables 2 and 3 were arranged into two choice set conditions allowing for binary analysis of the four choice conditions. The selections were now: option 1 vs. option 2, option 1 vs. option 3, option 1 vs. option 4, option 2 vs. option 3, option 2 vs. option 4, and option 3 vs. option 4 . The differences in travel time between the two selections were separated into the change in freeway travel time and the change in ramp time wait for each of the six selections, as shown in Table 4 for Experiment \#1 and in Table 5 for Experiment \#2. The first preference was the change in freeway travel time and the second preference was the change in ramp wait time. Each individual's preference was determined for the six selections.

Table 2

Choice set options and respondent preferences Experiment \#1

\begin{tabular}{llllll}
\hline $\begin{array}{l}\text { Option } \\
\text { number }\end{array}$ & $\begin{array}{l}\text { Freeway } \\
\text { time }(\mathrm{min})\end{array}$ & $\begin{array}{l}\text { Ramp } \\
\text { time }(\mathrm{min})\end{array}$ & $\begin{array}{l}\text { Total travel } \\
\text { time }(\mathrm{min})\end{array}$ & $\begin{array}{l}\text { Number of } \\
\text { CASP subjects }\end{array}$ & $\begin{array}{l}\text { Number of } \\
\text { VESP \#1 subjects }\end{array}$ \\
\hline 1 & 20 & 0 & 20 & 15 & 0 \\
2 & 15 & 2 & 17 & 17 & 1 \\
3 & 12 & 4 & 16 & 11 & 1 \\
4 & 10 & 6 & 16 & 1 & 15 \\
\hline
\end{tabular}

Table 3

Choice set options and respondent preferences Experiment \#2

\begin{tabular}{|c|c|c|c|c|c|}
\hline $\begin{array}{l}\text { Option } \\
\text { number }\end{array}$ & $\begin{array}{l}\text { Freeway } \\
\text { time (min) }\end{array}$ & $\begin{array}{l}\text { Ramp } \\
\text { time (min) }\end{array}$ & $\begin{array}{l}\text { Total travel } \\
\text { time (min) }\end{array}$ & $\begin{array}{l}\text { Number of } \\
\text { CASP subjects }\end{array}$ & $\begin{array}{l}\text { Number of } \\
\text { VESP \#2 subjects }\end{array}$ \\
\hline 1 & 20 & 0 & 20 & 16 & 3 \\
\hline 2 & 18 & 2 & 20 & 15 & 3 \\
\hline 3 & 16 & 4 & 20 & 11 & 7 \\
\hline 4 & 14 & 6 & 20 & 2 & 4 \\
\hline
\end{tabular}

Table 4

Selection set for the CASP Experiment \#1 and VESP \#1

\begin{tabular}{|c|c|c|}
\hline Selection & $\begin{array}{l}\text { Change in freeway } \\
\text { travel time (min) }\end{array}$ & $\begin{array}{l}\text { Change in ramp } \\
\text { wait time (min) }\end{array}$ \\
\hline Option 1 vs. 2 & 5 & -2 \\
\hline Option 1 vs. 3 & 8 & -4 \\
\hline Option 1 vs. 4 & 10 & -6 \\
\hline Option 2 vs. 3 & 3 & -2 \\
\hline Option 2 vs. 4 & 5 & -4 \\
\hline Option 3 vs. 4 & 2 & -2 \\
\hline
\end{tabular}


Table 5

Selection set for the CASP Experiment \#2 and VESP \#2

\begin{tabular}{|c|c|c|}
\hline Selection & $\begin{array}{l}\text { Change in freeway } \\
\text { travel time (min) }\end{array}$ & $\begin{array}{l}\text { Change in ramp } \\
\text { wait time (min) }\end{array}$ \\
\hline Option 1 vs. 2 & 2 & -2 \\
\hline Option 1 vs. 3 & 4 & -4 \\
\hline Option 1 vs. 4 & 6 & -6 \\
\hline Option 2 vs. 3 & 2 & -2 \\
\hline Option 2 vs. 4 & 4 & -4 \\
\hline Option 3 vs. 4 & 2 & -2 \\
\hline
\end{tabular}

The CASP subjects' data of demographic, socioeconomic, and personality characteristics were combined with the their preference of the six selections in Table 5 (Experiment \#1) to determine a linear model using the logit model estimated with the statistical software, STATA 7.0. Various combinations of the personality scores, age, sex, the length of time at their current residence, the dwelling type: single-family home unattached or either a duplex, condominium, or an apartment complex, if the subject rented or owned their place of residence, the educational level, the number of members in the household, the number of children under the age of 5 years old in the household, the number of adults and students in the household, the number of household members employed, the number of vehicles, bikes, and licensed drivers in the household, the model year of household vehicles in service, the combined household income, the one-way commute time, and the individual's total daily travel time were tested in various combinations until a model with variables significant at the 90 percent confidence level was established. In all cases of the model, the dependent variable is the option with the higher ramp wait time. The probabilities for each selection were calculated in STATA 7.0 using a binary logit model with the variables entered linearly. The total number of selections was 264, (44 subjects by 6 options).

\section{Hypotheses}

It is posited that the personality of the individual and certain demographic factors, such as age and sex, would correlate with the subject's preference for freeway congestion rather than ramp delay. The direction of correlation of demographic factors cannot be posited a priori due to lack of similar studies, though these factors do affect preferences in most travel behavior analyses. Similarly, personality scores have not been tested in this context in previous studies, but have been correlated with many other behaviors, including willingness to wait. It is expected that some personality factors will be correlated with resulting preferences. With regards to the effects of personality on preferences, this is an exploratory analysis, and so we make no predictions.

Daily travel behavior is believed to have an effect on waiting preference. Subjects who spend more time in travel, both commuting and other purpose trips, are posited to be more tolerant of ramp meter delay, since the main purpose of ramp metering is to create a more efficient travel flow on the freeways and shorten overall travel time, and those travelers will recall ramp delay as a shorter proportion of the total trip. It has been observed that ramp meters benefit long distance travelers over short distance travelers. (Zhang \& Levinson, 2002)

\section{Results}

Table 6 summarizes the descriptive statistics of the variables for the CASP, VESP \#1, and VESP \#2 subjects. The results for the experiments, including the values of coefficients ( $\beta$ 's) and their $z$-statistics are shown in Table 7. The variables are addressed in turn.

The coefficients for the change in freeway travel time and the change in ramp wait time are expected to have negative signs because an increase in travel time reduces utility. This was borne out in CASP \#1, in which case the variables were negative and significant, displaying a 64 percent increase in dislike for waiting at ramp meters over waiting on the freeway. The variable for freeway travel time was insignificant in the other cases. The change in ramp time was positive and significant in VESP \#1, which is in contrast with hypothesis. Reasons for this will be discussed in the next section. Change in ramp time was co-linear with change in freeway time in CASP \#2 and VESP \#2 and so was not included. 
Table 6

Descriptive statistics: mean (standard deviation) for subject sample sets

\begin{tabular}{llll}
\hline Variables & $\begin{array}{l}\text { CASP mean } \\
\text { (std. dev.) }\end{array}$ & $\begin{array}{l}\text { VESP \#1 mean } \\
\text { (std. dev.) }\end{array}$ & $\begin{array}{l}\text { VESP \#2 mean } \\
\text { (std. dev.) }\end{array}$ \\
\hline$N$ (male/female) & $44(12 / 32)$ & $17(9 / 8)$ & $17(10 / 7)$ \\
Average vehicle age & $7.1(4.5)$ & $7.9(3.3)$ & $7.4(3.9)$ \\
Subject age & $45.5(10.6)$ & $39.8(8.9)$ & $41.5(12.6)$ \\
One-way commute (min) & $35(18)$ & $38(16)$ & $29(13)$ \\
Total daily travel (min) & $96(39)$ & $105(45)$ & $97(33)$ \\
Neurotic & $15.9(6.7)$ & $13.2(6.5)$ & $14.5(5.0)$ \\
Extraversion & $27.8(7.2)$ & $32.7(5.1)$ & $27.2(6.8)$ \\
Openness & $30.4(7.0)$ & $28.5(5.3)$ & $30.9(7.3)$ \\
Agreeableness & $35.7(5.4)$ & $36.0(5.5)$ & $33.6(4.7)$ \\
Conscientiousness & $35.1(6.8)$ & $34.8(6.2)$ & $33.2(5.4)$ \\
\hline
\end{tabular}

Table 7

Model results: dependent variable is the option with the higher ramp wait time

\begin{tabular}{|c|c|c|c|c|c|c|}
\hline Variable & Coefficient & $z$ & $P>|z|$ & Coefficient & $z$ & $P>|z|$ \\
\hline & $C A S P \# 1$ & & & $V E S P \# 1$ & & \\
\hline Change in freeway time $(F)(\mathrm{min})$ & -0.854 & -6.29 & $0.000^{*}$ & 0.405 & 1.45 & 0.147 \\
\hline Change in ramp time $(R)(\mathrm{min})$ & -1.404 & -5.80 & $0.000^{*}$ & 1.073 & 1.99 & $0.046^{*}$ \\
\hline $\operatorname{Sex}(S)(1=$ male, $0=$ female $)$ & -1.410 & -3.50 & $0.000^{*}$ & -3.639 & -2.62 & $0.009^{*}$ \\
\hline Age $(A)$ & 0.029 & 1.92 & $0.055^{*}$ & -0.077 & -1.36 & 0.173 \\
\hline Average vehicle age $(V)$ & 0.162 & 3.87 & $0.000^{*}$ & -0.196 & -0.76 & 0.448 \\
\hline Neurotic score $(N)$ & 0.045 & 1.65 & $0.098^{*}$ & -0.016 & -0.22 & 0.828 \\
\hline Extraversion score $(E)$ & -0.053 & -2.18 & $0.029^{*}$ & -0.149 & -1.15 & 0.251 \\
\hline Openness score $(O)$ & 0.059 & 2.10 & $0.035^{*}$ & -0.111 & -0.75 & 0.451 \\
\hline Commute time $(C)(\min )$ & -0.025 & -1.83 & $0.068^{*}$ & 0.111 & 1.91 & $0.056^{*}$ \\
\hline Total daily travel time $(T)$ (min) & 0.014 & 2.10 & $0.036^{*}$ & 0.008 & 0.40 & 0.689 \\
\hline \multirow[t]{2}{*}{ Constant } & -2.679 & -1.49 & 0.136 & 8.323 & 1.66 & $0.097^{*}$ \\
\hline & $C A S P \# 2$ & & & $V E S P \# 2$ & & \\
\hline Change in freeway time $(F)(\min )$ & 0.054 & 0.56 & 0.572 & -0.096 & -0.66 & 0.507 \\
\hline Change in ramp time $(R)(\min )$ & - & - & - & - & - & - \\
\hline $\operatorname{Sex}(S)(1=$ male, $0=$ female $)$ & -1.621 & -4.45 & $0.000^{*}$ & -0.109 & -0.17 & 0.866 \\
\hline Age $(A)$ & 0.020 & 1.41 & 0.159 & 0.033 & 1.10 & 0.273 \\
\hline Average vehicle age $(V)$ & 0.102 & 2.74 & $0.006^{*}$ & 0.054 & 0.70 & 0.483 \\
\hline Neurotic score $(N)$ & -0.024 & -0.98 & 0.326 & 0.103 & 1.25 & 0.210 \\
\hline Extraversion score $(E)$ & -0.063 & -2.79 & $0.005^{*}$ & 0.003 & 0.06 & 0.949 \\
\hline Openness score $(O)$ & 0.051 & 1.96 & $0.050^{*}$ & -0.007 & -0.12 & 0.902 \\
\hline Commute time $(C)(\mathrm{min})$ & -0.009 & -0.77 & 0.443 & -0.028 & -1.12 & 0.261 \\
\hline Total daily travel time $(T)(\mathrm{min})$ & 0.004 & 0.61 & 0.543 & 0.012 & 1.06 & 0.291 \\
\hline Constant & 0.100 & 0.06 & 0.952 & -3.525 & -0.70 & 0.486 \\
\hline
\end{tabular}

${ }^{*}$ Indicates statistically significant at $90 \% \mathrm{CI}$.

Compared with females, males preferred congested freeway travel to higher ramp waits in three of the four cases, indicated by the negative and significant coefficients of the model.

The subject's age variable was entered as the numerical value and was significant in CASP \#1, where younger subjects tolerated freeway congestion more than older subjects. The variable in the other experiments was insignificant.

The average age of all vehicles in service (in years) was positive and significant in CASP \#1 and \#2 and insignificant in VESP \#1 and \#2. The CASP results indicate that subjects with older vehicles are more willing to tolerate ramp delay than those with newer cars.

The two travel behaviors that were tested in the model were one-way commute time and total daily travel time. In CASP \#1, individuals with a higher one-way commute time displayed a relative preference for freeway 
Table 8

CASP \#1 preference model correct prediction results

\begin{tabular}{lll}
\hline Subject's preference & Model predicted & Ramp delay $(\%)$ \\
\cline { 2 - 3 } & Freeway congestion $(\%)$ & 12 \\
\hline Freeway congestion & 88 & 60 \\
Ramp delay & 40 & \\
\hline
\end{tabular}

congestion, which contradicted the hypothesis. However the results from VESP \#1 comport with the hypothesis. The variable was insignificant in CASP \#2 and VESP \#2. It was believed that the longer the commute time, the more likely the subjects would prefer ramp meter wait in order to have a faster travel speed on the freeway. It is possible that subjects with the longer commute times have more flexible schedules at the University and may be leaving either earlier or later than peak-hour to avoid congested traffic conditions. In contrast, in CASP \#1, subjects with a higher total daily travel time variable displayed greater tolerance for ramp delay, which was expected. Total daily travel time was insignificant in the other three cases.

The household income variable was analyzed by grouping the income into 16 levels, 3 levels (low, medium, and high), and by a dollar amount range. All three groups resulted in no correlation between a preference for freeway travel time or ramp time. The remaining variables had no correlation concerning a preference for either condition and were dropped from the final regression.

The personality scores for $\mathrm{N}, \mathrm{E}$, and $\mathrm{O}$ were significant in the CASP \#1 and E and $\mathrm{O}$ were significant in CASP \#2. The $\mathrm{N}$-score is the neuroticism score, which is the level that an individual experiences negative thoughts or emotional distress. Subjects that scored higher on this attribute expressed more tolerance for waiting at the ramp meter. The E-score is the extraversion score, which is how an individual behaves in social situations. Subjects that score higher on this attribute expressed more tolerance for freeway congestion in both CASP \#1 and CASP \#2. The O-score is the level the individual is "open" to new creative or educational experiences. The higher the $\mathrm{O}$-score the more the individual accepted ramp delay, which was consistent in both CASP \#1 and CASP \#2.

It was determined that 65 percent of the selections indicated a preference for the option with relatively more freeway congestion and less ramp delay in CASP \#1. In CASP \#2, the preference for a slower freeway travel speed over a longer ramp wait time, increased from $65 \%$ to $68 \%$ when the total travel time was the same for all four conditions.

The VESP \#1 subjects preferred ramp delay in $81 \%$ of the 102 selection preferences, $(17$ subjects by 6 options), which is opposite of the CASP results. In VESP \#2, the preference for a slower freeway travel speed over a longer ramp wait time doubled from $19 \%$ to $40 \%$ when the total travel time was the same for all four conditions.

The probabilities for each selection were separated out into four categories. The categories were: subject selected freeway congestion-model predicted freeway congestion, subject selected freeway congestion-model predicted ramp delay, subject selected ramp delay-model predicted freeway congestion, and subject selected ramp delay-model predicted ramp delay. The definition of a correct prediction was that the probability was greater than 0.50 . The percent correct of the four categories are shown in Table 8 for CASP \#1, the case with the best prediction. Overall the model had a $78 \%$ correct prediction rate using a probability of 0.50 or better as the decision point for both preferences. Arranging the probability values from the largest to the smallest, the top $65 \%$ of the sample selection probabilities were compared with the preference for freeway congestion to determine the number of correct predictions, again using a probability value of 0.50 or better. This method gave the model an $82 \%$ correct prediction rate. As indicated by the fewer significant variables, the prediction success was lower on the other models.

\section{Discussion}

The subjects for both experiments were drawn from the same sample set and the descriptive statistics of the subjects were similar. The subjects were told in both methods to consider both freeway travel and ramp wait times as a complete condition, but the two methods had conflicting results. Subjects using the CASP method 
preferred the slower congested freeway condition over waiting longer at a ramp meter combined with a faster freeway travel condition. Subjects using the VESP method preferred the opposite. Each of the three sample data sets displayed over $70 \%$ of the subjects residing at their current residence for over 2 years, so differing memories of the Minneapolis-St. Paul metropolitan area ramp meter shutdown in the Fall of 2000 cannot explain the differences in the CASP and VESP subject's preferences. Why differing preference results?

One topic that many researchers, such as Yarmey (2000) have analyzed is an individual's estimation of time duration. The estimation of time philosophy is that "short" time periods are perceived as being longer and "long" time periods are perceived as being shorter. This is referred to as "Vierordt's Law" (Yarmey, 2000). The CASP subjects graphically visualized the overall shorter commute time benefit when selecting a longer ramp wait time, but 39\% preferred ramp wait times of 2 min and 34\% preferred ramp wait times of 0 min in Experiment \#1. The VESP \#1 subjects experienced "real-time" conditions with no activity, such as music or a cell phone to occupy them while they waited at the ramp meter. Time should have been perceived as passing slowly. The hypothesis suggests that the VESP \#1 subjects should have preferred the freeway travel time, but $88 \%$ preferred the ramp wait time of 6 min. Thus, perception of time did not affect results as predicted by Vierordt's Law.

Another possibility is that individuals rely on their memory or past experiences when making their decisions or expressing preferences. The CASP subjects were presented with the ramp wait time and freeway travel time conditions together graphically. They had to rely on their past driving experiences. The speed was stated as being constant for the time periods and subjects may have accepted that moving was better than waiting. They may have had trouble recalling how slow one speed actually is in comparison to the next. The VESP subjects experienced the ramp wait time first followed by traffic conditions that were not at a steady rate. The traffic conditions presented may have been significantly more uncomfortable than what they experienced in their actual commute. Thus, their preferences for the longer ramp wait time condition with less congested freeway conditions.

The two methods present the information differently and ask for assessment at different times. The CASP experiments present the two travel times simultaneously and then record preferences while the VESP presents the two travel times in sequence, and at the end of the sequence asks for a preference to be expressed. In this case, the freeway travel time is more recent, and thus may be remembered more clearly as onerous, while the boring ramp delay is a distant memory, which is consistent with reported outcomes.

The differences between the two experimental methods likely explain the conflicting results in the subjects' preferences. The CASP method involves a shorter experiment time span, the speeds are presented graphically as a constant speed on a computer monitor, and the subject's rely on their recall of previous driving experiences in determining their preferences. The VESP method involved real-time simulated conditions in an actual vehicle using projectors and screens to replicate traffic conditions from the behind the wheel. The driving simulation presented varying travel speeds throughout each run, which averaged out to the appropriate freeway speed for that option. It replicated stop-and-go congested freeway conditions. The congested freeway conditions might have been worse than what the subjects experience in their actual commute. This might also explain why they preferred the longer ramp delay to a longer freeway travel time.

Which one of these methods is most correct is difficulty to say, in that they replicate different aspects of the commute. While the VESP is more similar to an actual commute, the CASP relies on the driver to recall a specific commute. Moreover the VESP suffers from recency effects. In any case, the lack of consistency in the two methods does call for additional research into both methodology for ascertaining these types of values as well as research into the specific values travelers hold about waiting time vs. congested moving time.

\section{Summary and conclusions}

Driver's waiting tolerance for ramp meter delay and freeway traffic congestion were analyzed in our research. The subject's demographics, socioeconomic characteristics, travel time conditions, and personality trait scores were compared with their preference for either ramp delay or freeway congestion by two different experiment methods. The first method was a traditional stated preference survey in a computer format, known as CASP (computer administered stated preference). This method presented the options on a computer screen in bar graph form. The subjects were asked which option they preferred. The second method presented the 
freeway and ramp travel times to subjects who experienced the conditions in a state of the art driving simulator. This method, called VESP (virtual experience stated preference) replicated a realistic freeway drive in terms of timing and sequence.

Subjects' preferences for increasing ramp wait times combined with decreasing freeway congestion were obtained for several experimental conditions. Experiment \#1 travel time conditions had four options with $0,2,4$, or 6 min of ramp delay combined with increasing freeway travel speed that resulted in a shorter overall total travel time of 20,17, 16, and 16 min respectively. Experiment \#2 travel time condition had four options with $0,2,4$, or 6 min of ramp delay combined with increasing freeway travel speed that resulted in the same total travel time of $20 \mathrm{~min}$ in all options. The total distance traveled was the same $16 \mathrm{~km}$ (10 miles) in both conditions. The CASP subjects were the same for both experiments, whereas in the VESP method, the subjects who undertook Experiment \#1 were different than those who undertook Experiment \#2 due to time constraints. Each VESP experiment averaged around 90 min per subject to complete.

The CASP subject's personal characteristics and preferences from Experiment \#1 were analyzed using a binary logit model with the variables entered linearly, to derive a preference time utility model. The variables that were significant included the subject's sex, age, average age of vehicles, personality scores from the NEO Five-Factor test for Neuroticism, Extraversion, and Openness, one-way commute time, total daily travel time, freeway travel time, and ramp wait time. Variables that remained significant for Experiment \#2 were sex, average age of vehicles, and personality scores for Extraversion and Openness. Applying this model to the VESP Experiment \#1 only the subjects' sex, one-way commute time, and the change in ramp time variables were significant. None of the variables from the CASP model were significant for the VESP Experiment \#2.

Ramp metering has been demonstrated to reduce overall freeway system travel time, but this does not necessarily benefit each individual driver, suggesting some type of social dilemma. This paper considered ramp metering as a trade-off made within-individuals, though it is also for many travelers a trade-off made between individuals. Some drivers must wait in order to keep the overall freeway moving. Educating the driving public about the use and benefits of ramp metering might persuade them to tolerate them as they would tolerate other types of waiting. Piotrowicz and Robinson (1995) stated that a public relations agency in New York changed the name of ramp meters to "merge lights" in order to instill a more positive view of ramp metering. Informing drivers of the ramp wait time may improve opinion of them. Even with an excellent public relations campaign for ramp metering, transportation officials must balance the travel times on the freeway network in order to preserve equity for all drivers.

\section{Acknowledgements}

The University of Minnesota's Intelligent Transportation Systems Institute project "Ramp Meter Delays, Freeway Congestion, and Driver Acceptance" provided funding for this research. The authors would like to thank Kasia Winiarczyk for her assistance in the design and administration of the study and Kristin Deutsch, Nova Schuler, Grace Deason, and Ben Chihak for their assistance with the driving simulation experiments. We would also like to thank two anonymous reviewers for their suggestions.

\section{References}

Arthur, W., \& Graziano, W. (1996). The five-factor model, conscientiousness, and driving accident involvement. Journal of Personality, 64, $593-618$.

AutoSim (2002). Technical documentation. AutoSim. Norway.

Buchanan, T. (2001). Online implementation of an IPIP five factor personality inventory. Available from http://users.wmin.ac.uk/ buchant/wwwffi/introduction.html.

Cellar, D. F., Nelson, Z. C., \& Yorke, C. M. (2000). The five-factor model and driving behavior: Personality and involvement in vehicular accidents. Psychological Reports, 86, 454-456.

Chaudhary, N., \& Messer, C. (2000). Ramp-metering technology and practice: Tasks 1 and 2 summary, report 2121-1. College Station, TX: Texas Transportation Institute.

Chen, C., Jia, Z., \& Varaiya, P. (2001). Causes and cures of highway congestion. IEEE Control Systems Magazine, 21(4), $26-33$.

Costa, P., Jr., \& McCrae, R. (1991). NEO five-factor inventory form S. Florida: Psychological Assessment Resources Inc.

D'Arcier, B. (2000). Hypothetical situations the attempt to find new behavioral hypotheses. Available from http://gulliver.trb.org/ publications/circulars/ec008/workshop_1.pdf. 
Hensher, D., \& Battelino, H. (1997). The role of stated preferences and discrete-choice models in identifying individual preferences for traffic management devices. In P. Stopher \& M. Lee-Gosselin (Eds.), Understanding travel behavior in an era of change (pp. 233-256). Oxford, United Kingdom: Pergamon, Elsevier Science Ltd.

Levinson, D., Harder, K., Bloomfield, J., \& Winiarczyk, K. (2005). Ramp meter delays, freeway congestion, and driver acceptance: Final report (CTS05-02). Minneapolis, MN: Intelligent Transportation Systems Institute, University of Minnesota.

Levinson, D., \& Zhang, L. (in press). Ramp meters on trial: Evidence from the twin cities ramp meter holiday. Transportation Research Part $A$.

Louviere, J., Hensher, D., \& Joffre, D. (2000). Stated choice methods analysis and application. Cambridge, United Kingdom: Cambridge University Press.

Moberg, D. (1999). The big five and organizational virtue. Business Ethics Quarterly, 9(2), 245-272.

Pearson, R., Black, J., \& Wanat, J. (2001). ITS decision a gateway to understanding and applying intelligent transportation systems. Available from http://www.path.berkeley.edu/itsdecision/serv_and_tech/Ramp_metering/ramp_metering_report.htm.

Piotrowicz, G., \& Robinson, J. (1995). Ramp metering status in North America-1995 update. Washington, DC: US Department of Transportation.

Polak, J., \& Jones, P. (1997). Using stated-preference methods to examine traveler's preferences and responses. In P. Stopher \& M. LeeGosselin (Eds.), Understanding travel behavior in an era of change (pp. 177-208). Oxford, United Kingdom: Pergamon, Elsevier Science Ltd.

Stern, E., \& Richardson, H. (2002). Behavioral modeling of road users - current research and future needs. Available from http:// www.stellaproject.org/FocusGroup3/Washington/Papers/Stern-Richardson.doc.

Stopher, P., \& Zmud, J. (2001). SP applications. In D. Hensher (Ed.), Travel behavior research the leading edge (pp. 299-308). Oxford, United Kingdom: Pergamon, Elsevier Science Ltd.

Tokar, D., Fischer, A., Snell, A., \& Harik-Williams, N. (1999). Efficient assessment of the five-factor model of personality: Structural validity analyses of the NEO five-factor inventory (Form S). Measurement and Evaluation in Counseling and Development, 32, 14-30.

$\mathrm{Wu}$, J. (2001). Traffic diversion resulting from ramp metering. Master of Science in Engineering Thesis, University of Wisconsin, Milwaukee.

Yarmey, A. (2000). Retrospective duration estimations for variant and invariant events in field situations. Applied Cognitive Psychology, $14,45-57$.

Zhang, L., \& Levinson, D. (2002). Estimation of the demand response to ramp metering. In Proceedings of international conference on traffic and transportation studies (pp. 674-681). Washington, DC: American Society of Civil Engineers. 